\title{
The manifestation of the 10 personality aspects amongst the facets of the Basic Traits Inventory
}

\begin{tabular}{|c|c|}
\hline $\begin{array}{l}\text { Authors: } \\
\text { Xander van Lil } \\
\text { Nicola Taylor }\end{array}$ & (D) \\
\hline $\begin{array}{l}\text { Affiliations: } \\
{ }^{1} \text { Department } \\
\text { Psychology an } \\
\text { Management, } \\
\text { Business and } \\
\text { University of J } \\
\text { Johannesburg }\end{array}$ & $\begin{array}{l}\text { f Industrial } \\
\text { d People } \\
\text { College of } \\
\text { Economics, } \\
\text { ohannesburg, } \\
\text { South Africa }\end{array}$ \\
\hline $\begin{array}{l}{ }^{2} \text { Product and } \\
\text { Africa Group, } \\
\text { South Africa }\end{array}$ & $\begin{array}{l}\text { Research, JVR } \\
\text { Johannesburg, }\end{array}$ \\
\hline $\begin{array}{l}{ }^{3} \text { Data Enablem } \\
\text { Group, Johann } \\
\text { South Africa }\end{array}$ & $\begin{array}{l}\text { ent, JVR Africa } \\
\text { esburg, }\end{array}$ \\
\hline $\begin{array}{l}\text { Correspondin } \\
\text { Xander van Lil } \\
\text { xvanlill@gmai }\end{array}$ & $\begin{array}{l}\text { g author: } \\
\text { I, } \\
\text { l.com }\end{array}$ \\
\hline $\begin{array}{l}\text { Dates: } \\
\text { Received: } 16 \mathrm{~J} \\
\text { Accepted: } 15 \\
\text { Published: } 30\end{array}$ & $\begin{array}{l}\text { uly } 2020 \\
\text { =eb. } 2021 \\
\text { Mar. } 2021\end{array}$ \\
\hline $\begin{array}{l}\text { How to cite th } \\
\text { Van Lill, X., \& } \\
\text { (2021). The m } \\
\text { the } 10 \text { person } \\
\text { amongst the } \mathrm{f} \\
\text { Basic Traits In } \\
\text { Journal of Psyc } \\
\text { Assessment, } 3 \\
\text { https://doi.org } \\
\text { ajopa.v3i0.31 }\end{array}$ & $\begin{array}{l}\text { is article: } \\
\text { Taylor, } N \text {. } \\
\text { anifestation of } \\
\text { ality aspects } \\
\text { acets of the } \\
\text { /entory. African } \\
\text { chological } \\
(0) \text {, a31. } \\
\text { (10.4102/ }\end{array}$ \\
\hline $\begin{array}{l}\text { Copyright: } \\
\text { (C) 2021. The A } \\
\text { Licensee: AOS } \\
\text { is licensed unc } \\
\text { Creative Comn } \\
\text { Attribution Lic }\end{array}$ & $\begin{array}{l}\text { uthors. } \\
\text { IS. This work } \\
\text { ler the } \\
\text { nons } \\
\text { ense. }\end{array}$ \\
\hline Read online: & \\
\hline 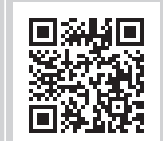 & $\begin{array}{l}\text { Scan this QR } \\
\text { code with your } \\
\text { smart phone or } \\
\text { mobile device } \\
\text { to read online. }\end{array}$ \\
\hline
\end{tabular}

Personality traits play an important role in the prediction of important work-related outcomes. Adapting the level at which personality constructs are measured can assist in predicting workrelated outcomes at the corresponding level of specificity with greater accuracy. This study investigates whether eight hierarchical factors (also referred to as personality aspects) manifest amongst the facets of the Basic Traits Inventory (BTI). The study is based on an archival dataset of 1359 South African employees. Orthogonal first-order, single-factor, higher-order, oblique lower-order and bifactor models were specified to investigate the hierarchical structure of eight of the 10 personality aspects. The evidence supports the notion that seven of the 10 personality aspects (as measured by the BTI) could be more parsimoniously interpreted as total scores, but not necessarily hierarchical factors, amongst South African employees. It is, therefore, practically meaningful for practitioners to calculate such scores when the need arises for more detailed levels of prediction when selecting applicants or developing employees.

Keywords: 10 personality aspects; Basic Traits Inventory; bifactor structure; hierarchical factor analysis, bandwidth-fidelity.

\section{Introduction}

Personality predicts several important criteria in the workplace, such as job performance, team effectiveness, leadership effectiveness and motivation (Ones, Dilchert, Viswesvaran, \& Judge, 2007). A meta-analysis conducted by Van Aarde, Meiring and Wiernik (2017) in South Africa, which included predictive studies based on the Basic Traits Inventory (BTI), reaffirmed the predictive validity of personality traits, especially conscientiousness, for technical, training, contextual and counterproductive performance. However, there is a continuing debate regarding the predictive validity of the five broad traits versus their constituent personality facets (see Figure 1) for job performance (Judge, Rodell, Klinger, Simon, \& Crawford, 2013). Some argue that the five broad traits are more robust predictors of job performance (Barrick \& Mount, 2005; Ones, Viswesvaran, \& Dilchert, 2005), whereas others argue each broad trait's facets enable researchers and practitioners to better exploit predictive validity at specific levels of job performance (Anglim \& Grant, 2014; Pletzer, Oostrom, Bentvelzen, \& De Vries, 2020; Tett, Steele, \& Beauregard, 2003). Cronbach and Gleser (1965) captured an important aspect of this debate by referring to it as the bandwidth-fidelity dilemma where '...there is some ideal compromise between a variety of information (bandwidth) and thoroughness of testing to obtain more certain information (fidelity)' (p. 100).

DeYoung, Quilty, \& Peterson (2007) found evidence to support a hierarchical level of personality between the broad five traits and their constituent facets, referred to as the 10 aspects of personality (see Figure 1), based on the measures of Abridged Big Five Circumplex (Hofstee, De Raad, \& Goldberg, 1992) and NEO Personality Inventory-Revised (NEO-PI-R; Costa \& McCrae, 1992). Judge et al. (2013) provide evidence that the 10 personality aspects have a distinct advantage over broad personality traits in that they more coherently represent the unique correlations between personality facets. Judge et al. (2013) further provide evidence that 10 personality aspects offer predictive gains over five broad traits when narrower aspects of job performance are measured.

DeYoung et al.'s (2007) findings on the 10 personality aspects had a considerable impact in the United States of America, boasting a total of 321 citations at the time of the search on the Web of Science. Other countries citing DeYoung et al.'s (2007) work at the time included Canada (93), Australia (73), Germany (65), England (63), the Netherlands (34), New Zealand (20), Peoples Republic of China (16), Scotland (14) and Belgium (13). However, no replications of the 10 personality 


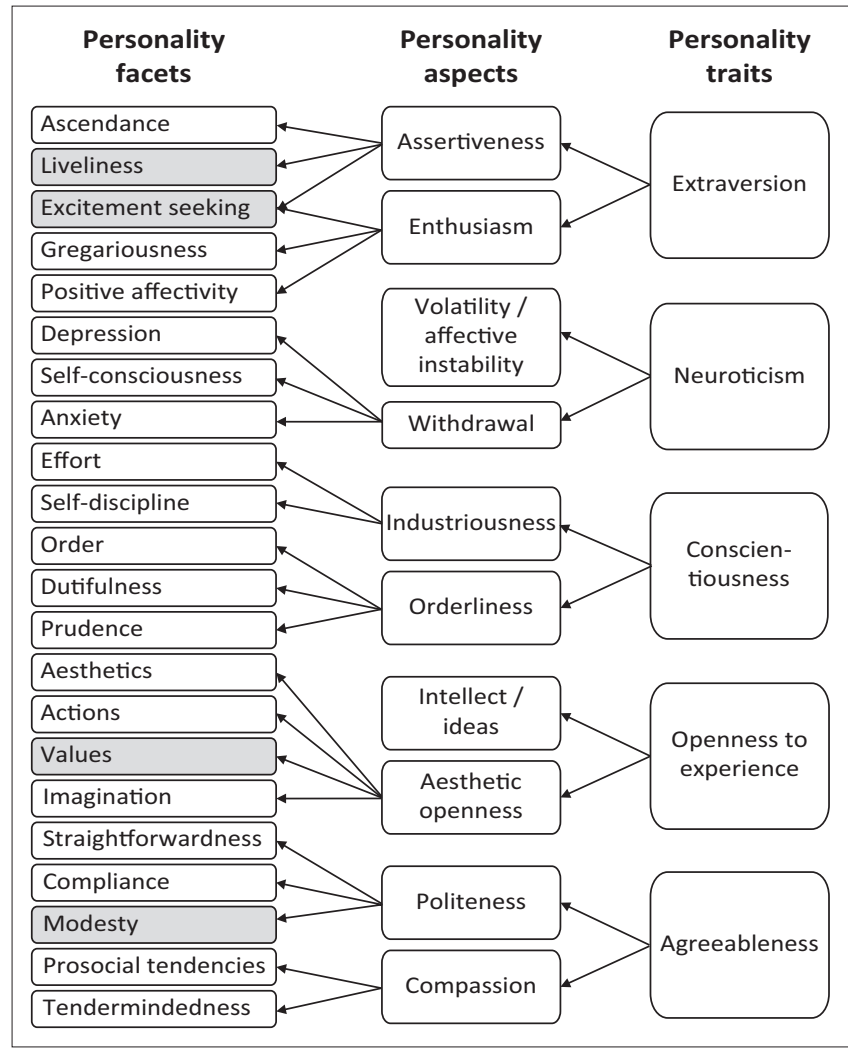

Source: Adapted from Judge, T.A., Rodell, J.B., Klinger, R.L., Simon, L.S., \& Crawford, E.R. (2013). Hierarchical representations of the five-factor model of personality in predicting job performance: Integrating three organizing frameworks with two theoretical perspectives. Journal of Applied Psychology, 98(6), 878. https://doi.org/10.1037/a0033901

FIGURE 1: A non-statistical representation of the hierarchical structure of the Basic Traits Inventory (Taylor \& De Bruin, 2017) based on DeYoung et al.'s (2007) typology and Judge et al.'s (2013) guidelines for the 10 personality aspects. On further analysis, facets in grey were removed due to low reliabilities and strength of inter-factor correlations reported.

aspects have been investigated in less developed parts of the Southern Hemisphere. It is becoming increasingly important to provide evidence on the replicability of personality models in non-WEIRD (white, educated, industrialised, rich and democratic) countries (Laajaj et al., 2019). Van de Vliert and Van Lange (2019) emphasise the need for a discipline called cross-latitudinal psychology to investigate the replicability of findings from the Northern Hemisphere to less developed parts of the Southern Hemisphere. South Africa is a middleincome country with 11 official languages with unique challenges in terms of its educational system (Department of Basic Education, 2019), economic growth (South African Reserve Bank, 2019), distribution of wealth (Statistics South Africa, 2019), as well as public sector corruption in terms of accountability, transparency and state capture (Transparancy International, 2019). An investigation of the hierarchical structure of eight of the 10 personality aspects in South Africa could provide practitioners in the region with a more parsimonious representation of facets whilst still allowing employers to make more nuanced personnel selection and development decisions. The intention of this article is not to argue against the five factors of personality in favour of the 10 personality aspects but to provide practitioners with alternative ways of interpreting the same results based on evidence (Wiernik, Yarkoni, Giordano, \& Raghavan, 2020). For example, based on Figure 1, when it is important to predict either quantity or quality of tasks performed, measures of Industriousness and Orderliness respectively might provide unique information.

Figure 1 visually depicts a hierarchical structure of personality based on the three levels proposed for the BTI in the present study, namely personality facets, aspects and traits. Agreeableness (trait), as an example from Figure 1, can be represented by two personality aspects, namely Politeness and Compassion. Politeness, in turn, is represented by Straightforwardness, Compliance and Modesty (facets) whereas Compassion is represented by Prosocial Tendencies and Tender-mindedness (facets). Arrows leading from personality traits to aspects, such as the arrows leading from Agreeableness to Politeness and Compassion, reflect a common factor at the trait level (Agreeableness). Similar to the findings of Judge et al. (2013) on the NEO-PI-R, some aspects, such as Volatility (represented by facet Affective Instability in the BTI) and Intellect (represented by facet Ideas in the BTI), are represented by one indicator only and therefore, do not represent a hierarchical composite.

\section{Research objective and hypotheses}

The current study aims to investigate the hierarchical structure of eight of DeYoung et al.'s (2007) 10 personality aspects from data collected on the BTI in South Africa (Taylor \& De Bruin, 2017). DeYoung et al.'s (2007) 10 personality aspects could be viewed as a hierarchical level of personality between the Big Five traits and its constituent facets. According to DeYoung et al. (2007), personality aspects might be a more parsimonious breakdown of the Big Five than the personality facets. Furthermore, when compared to personality facets, aspects might better represent the phenotypical patterns of thought, affect and behaviour (DeYoung et al., 2007; Jang, Livesley, Angleitner, Reimann, \& Vernon, 2002).

DeYoung et al. (2007) distinguish between two personality aspects on the trait Extraversion, namely Assertiveness and Enthusiasm. Assertiveness refers to an individual's agency or dominance, whereas Enthusiasm refers to outward friendliness. Following the guidelines of Judge et al. (2013), it is hypothesised that:

$\mathbf{H}_{1}$ : The personality aspect Assertiveness explains covariance between a set of items in Extraversion independent of the covariance that facets Ascendance, Liveliness and Excitement Seeking explained in the same set of items.

$\mathbf{H}_{2}$ : The personality aspect Enthusiasm explains covariance between a set of items in Extraversion independent of the covariance that facets Excitement Seeking, Positive Affectivity and Gregariousness explained in the same set of items.

Trait Neuroticism, according to DeYoung et al. (2007), can be divided between two personality aspects, namely Volatility and Withdrawal. Volatility refers to the outward expression of negative affect, as with irritability and aggression, whereas withdrawal refers to the internalisation of negative affect. The BTI had only one indicator for Volatility, which made 
the computation of a hierarchical composite unfeasible. However, as per Judge et al.'s (2013) guidelines on Withdrawal, it could be hypothesised that:

$\mathbf{H}_{3}$ : The personality aspect Withdrawal explains covariance between a set of items in Neuroticism independent of the covariance that facets Depression, Self-Conscious and Anxiety explained in the same set of items.

DeYoung et al. (2007) argue that trait Conscientiousness can be represented by two personality aspects, namely Industriousness and Orderliness. Whereas Industriousness refers to the tendency to be reliable and hardworking, Orderliness reflects a preference for perfectionism. Following the guidelines of Judge et al. (2013), it is hypothesised that:

$\mathbf{H}_{4}$ : The personality aspect Industriousness explains covariance between a set of items in Conscientiousness independent of the covariance that facets Effort and Self-Discipline explained in the same set of items.

$\mathbf{H}_{5}$ : The personality aspect Orderliness explains covariance between a set of items in Conscientiousness independent of the covariance that facets Order, Dutifulness and Prudence explained in the same set of items.

Trait Openness to Experience, according to De Young et al. (2007), composes of two personality aspects, namely Intellect and Aesthetic Openness. Intellect refers to an inclination towards creative ingenuity, whereas Aesthetic Openness reflects an appreciation for beauty in the world. Like the study conducted by Judge et al. (2013), Intellect is represented by one indicator only, namely Ideas, which makes the calculation of a hierarchical composite unfeasible. However, as per Judge et al.'s (2013) guidelines on Aesthetic Openness, it could be hypothesised that:

$\mathbf{H}_{6}$ : The personality aspect Aesthetic Openness explains covariance between a set of items in Openness to Experience independent of the covariance that facets Aesthetics, Actions, Values and Imagination explained in the same set of items.

DeYoung et al. (2007) distinguish between two personality aspects of Agreeableness, namely Politeness and Compassion. Politeness refers to an individual's tendency to be a pleasant person to be around, whereas Compassion reflects a tendency for social awareness and goodwill. Per the guidelines of Judge et al. (2013), it is hypothesised that:

$\mathbf{H}_{7}$ : The personality aspect Politeness explains covariance between a set of items in Agreeableness independent of the covariance that facets Straightforwardness, Compliance and Modesty explained in the same set of items.

$\mathbf{H}_{8}$ : The personality aspect Compassion explains covariance between a set of items in Agreeableness independent of the covariance that facets Prosocial Tendencies and Tendermindedness explained in the same set of items.

\section{Method \\ Participants}

The respondents were 1359 individuals of varying ages $($ mean $=28.33$ years, standard deviation $[S D]=7.44$ years $)$ who completed the BTI for selection ( $n=1019,75 \%)$ or development $(n=340,25 \%)$ purposes at various South African organisations. Most of the respondents were black African $(n=941,69 \%)$, followed by white $(n=197,14 \%)$, coloured (individuals of mixed ancestry; $n=92,7 \%$ ) and Indian $(63,5 \%)$. The sample comprised more men $(n=693$, $51 \%)$ than women $(n=666,49 \%)$. The majority of the respondents' first language was isiZulu ( $n=257,19 \%)$, followed by English $(n=237,17 \%)$, Sepedi $(n=146,11 \%)$, Afrikaans $(n=145,11 \%)$, Setswana $(n=143,11 \%)$, isiXhosa $(n=123,9 \%)$, Sesotho $(n=109,8 \%)$, Xitsonga $(n=80,6 \%)$, Tshivenda $(n=61,4 \%)$, SiSwati $(n=38,3 \%)$ and isiNdebele ( $n=15,1 \%$ ). Most of the respondents' highest qualification was grade $12(n=693,51 \%)$, followed by a diploma $(n=340$, $25 \%)$, bachelor's degree $(n=139,10 \%)$, less than matric $(n=73,5 \%)$, honour's degree $(n=50,4 \%)$, master's degree $(n=12,1 \%)$ and doctoral degree $(n=3,0.22 \%)$.

\section{Instruments}

Archival data on the BTI was used to inspect the manifestation of the 10 personality aspects amongst South African employees. The BTI is a measure of the five factors of personality and provides a further breakdown of 24 facets. A review of the technical manual on the BTI indicated that most of the facets, apart from Values (0.44) and Modesty (0.56), display good internal consistency reliabilities ( $\alpha \geq 0.64)$. Exploratory factor analysis supports the Big Five structure of the BTI. A calculation of congruence scores, between the factor structures for South Africans that self-identified as white or black African, supported the measurement invariance of the assessment across ethnic groups (Taylor \& De Bruin, 2017). The measure has 193 items and utilises a five-point Likert scale.

\section{Procedure}

The data were collected as part of several projects that have been conducted by the JVR Africa Group in different workplace settings. Data were collected via paper-and-pen or online assessments.

The study was low in risk, but precautions were taken to ensure that participation was voluntary and anonymous, no harm was caused, the questions were filled in truthfully and informed consent was given to use the results for research purposes.

\section{Data analysis}

\section{Descriptive statistics}

The internal consistency reliability of the scales in the respective measures was inspected by calculating Cronbach's alpha (Cronbach, 1951) and McDonald's omega (McDonald, 1999). Cronbach's alpha coefficient and McDonald's omega coefficient were calculated using Version $0.4-14$ of the semTools package in $R$ (Jorgensen, Pornprasertmanit, Schoemann, \& Rosseel, 2019) and are interpreted as estimates of internal consistency reliability (Revelle \& Zinbarg, 2009). 


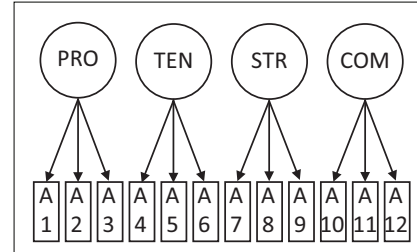

(1) Orthogonal first-order model

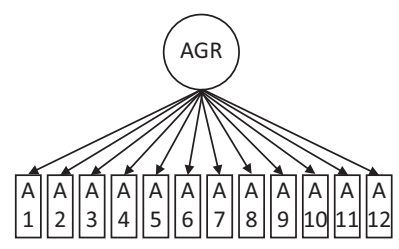

(2) Single-factor model

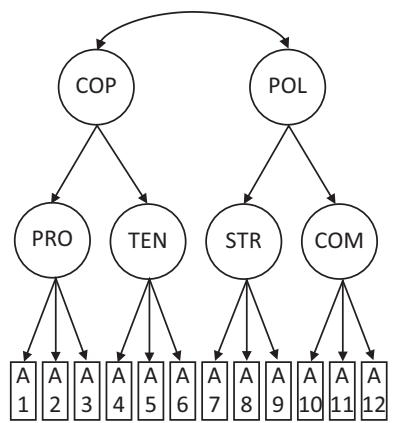

(3) Higher-order model

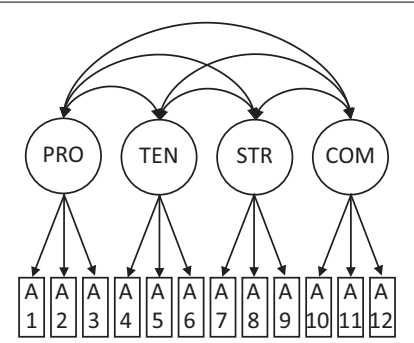

(4) Oblique lower-order model

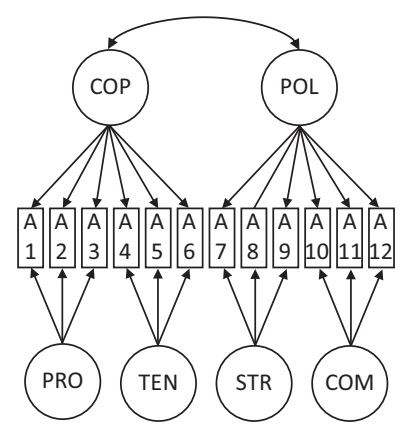

(5) Bifactor model

Source: Adapted from Credé, M., \& Harms, P.D. (2015). 25 years of higher-order confirmatory factor analysis in the organizational sciences: A critical review and development of reporting recommendations. Journal of Organizational Behavior, 36(6), 850. https://doi.org/10.1002/ job.2008

Note: AGR, agreeableness; COP, compassion; POL, politeness; PRO, prosocial tendencies; TEN, tendermindedness; STR, Straightforwardness; COM, Compliance.

FIGURE 2: Factor structures of agreeableness on the BTI based on Credé and Harms's (2015) guidelines.

\section{Confirmatory factor analysis}

Judge et al. (2013) conducted a higher-order confirmatory factor analysis (CFA) to inspect facet loadings on the secondorder personality aspects. Credé and Harms (2015) recommend that five sequential models are tested before it can be argued that hierarchical structure exists within a psychometric measure, namely (1) orthogonal first-order, (2) single-factor, (3) higher-order, (4) oblique lower-order, and (5) bifactor models. Figure 2 provides an example, based on agreeableness, on how each of the mentioned factor models is specified. Not all the items of agreeableness are visually displayed in Figure 2 (scale of the trait consists of 30 items).

As portrayed in Figure 2, both higher-order (3) and bifactor (5) models, represent hierarchical factor models. With higherorder models, personality facets mediate the relationship between the manifest variables and the second-order personality aspects (Beaujean, 2014). Consequently, the second-order personality aspects do not explain unique variance in the manifest variables over and above the personality facets (Beaujean, 2014; Mcabee, Oswald, \& Connelly, 2014). Bifactor models, in contrast, account for the unique variance explained in the manifest variables by the orthogonal personality aspects, over and above the variance explained by the orthogonal personality facets (Beaujean,

2014; Mcabee et al., 2014), which justifies bifactor models as the test models in this study. As presented in Figure 1, the aspects are specified to correlate in the hierarchical models because of the aspects' common variance at the trait level.

A CFA with weighted least square mean and variance (WLSMV) estimation was performed to inspect the interfactor correlations and hierarchical factor structures of the 10 personality aspects (Beauducel \& Yorck Herzberg, 2009; DiStefano, 2002; Li, 2016). The WLSMV estimation was chosen based on the recommendation of Li (2016), who indicated that WLSMV outperforms robust maximum likelihood (MLM) estimation when determining the parameter estimates and standard errors of factor loadings for items with scales consisting of five or more numerical categories. The multivariate skewness (1 374 251, $p<0.001$ ) and kurtosis $(212.41, p<0.001)$ for the entire set of 180 items (excluding the social desirability scale) further justified the use of a robust estimator (DiStefano \& Morgan, 2014). The fit was considered suitable if the RMSEA and SRMR were $\leq 0.08$ (Brown, 2006; Browne \& Cudeck, 1992) and comparative fit index (CFI) and Tucker-Lewis index (TLI) > 0.95 (Brown, 2006; Hu \& Bentler, 1999). Even if comparative fit indices display marginally good fit to the data (CFI and TLI in the range of 0.90 to 0.95 ), models might still be considered to display acceptable fit if other indices (SRMR and RMSEA) in tandem are in the acceptable range (Brown, 2006). Because of the lack of the log-likelihood value in WLSMV, the Akaike information criterion (AIC) (Akaike, 1987) and Schwarz's Bayesian information criterion (BIC) (Raftery, 1995) could not be calculated (Finch \& French, 2015). The chi-square statistic, including a comparison of the relative fit of different models (Vandenberg \& Lance, 2000), was used to compare each of the alternatives to the hypothesised models (Credé \& Harms, 2015).

\section{Ethical considerations}

Ethical approval to conduct the study was obtained from the Research Ethics Committee (Department of Industrial Psychology and People Management) at the University of Johannesburg on 30 June 2020 (reference no. IPPM-2020-431).

\section{Results \\ Descriptive statistics}

Table 1 provides the mean item score and standard deviation for each scale of the BTI, along with the alpha and omega reliability estimates and standardised inter-factor correlations of the facets comprising the Big Five traits. The inter-factor correlations were obtained by conducting oblique lowerorder confirmatory factor models. The indices of fit for Extraversion $\left(\chi^{2}[d f]=4280.58\right.$ [550]; CFI $=0.81$; TLI $=0.79$; SRMR $=0.09 ;$ RMSEA $=0.08$ [0.07; 0.08]) and Agreeableness $\left(\chi^{2}[d f]=4440.87\right.$ [550]; CFI $=0.84 ; \mathrm{TLI}=0.83 ; \mathrm{SRMR}=0.07$; RMSEA $=0.07$ [0.07; 0.08]) were less desirable but improved 
TABLE 1a: Inter-factor correlations of scales on Basic Traits Inventory. Extraversion.

\begin{tabular}{lcccc}
\hline Variables & Ascendance & Liveliness & Positive affectivity & Gregariousness \\
\hline Liveliness & $0.67^{*}$ & - & - & - \\
Positive affectivity & $0.45^{*}$ & $0.72^{*}$ & - & - \\
Gregariousness & $0.58^{*}$ & $0.64^{*}$ & $0.55^{*}$ & - \\
Excitement seeking & $0.12^{*}$ & $0.18^{*}$ & -0.01 & - \\
Mean & 3.64 & 3.62 & 4.16 & $0.21^{*}$ \\
Standard deviation & 0.67 & 0.60 & 0.54 & 3.77 \\
Alpha & 0.77 & 0.67 & 0.69 & 0.67 \\
Omega & 0.79 & 0.66 & 0.70 & 0.75 \\
\hline
\end{tabular}

$*, p<0.001$.

TABLE 1b: Inter-factor correlations of scales on Basic Traits Inventory. Neuroticism.

\begin{tabular}{lcccc}
\hline Variables & Affective instability & Depression & Self-consciousness & Anxiety \\
\hline Depression & $0.79^{*}$ & - & - & - \\
Self-consciousness & $0.65^{*}$ & $0.85^{*}$ & - & - \\
Anxiety & $0.68^{*}$ & $0.79^{*}$ & $0.85^{*}$ & - \\
Mean & 1.82 & 1.95 & 2.50 & - \\
Standard deviation & 0.68 & 0.64 & 0.73 & - \\
Alpha & 0.85 & 0.82 & 0.80 & - \\
Omega & 0.86 & 0.82 & 0.80 & - \\
\hline
\end{tabular}

$*, p<0.001$.

TABLE 1c: Inter-factor correlations of scales on Basic Traits Inventory. Conscientiousness.

\begin{tabular}{lcccc}
\hline Variables & Effort & Order & Dutifulness & Prudence \\
\hline Order & $0.67^{*}$ & - & - & - \\
Dutifulness & $0.76^{*}$ & $0.79 *$ & - & - \\
Prudence & $0.79^{*}$ & $0.76^{*}$ & $0.81^{*}$ & - \\
Self-discipline & $0.81^{*}$ & $0.78^{*}$ & $0.87^{*}$ & - \\
Mean & 4.33 & 4.28 & 4.35 & $0.84^{*}$ \\
Standard deviation & 0.51 & 0.55 & 0.48 & 4.42 \\
Alpha & 0.75 & 0.85 & 0.80 & 0.51 \\
Omega & 0.74 & 0.84 & 0.80 & 0.74 \\
\hline
\end{tabular}

$*, p<0.001$.

TABLE 1d: Inter-factor correlations of scales on Basic Traits Inventory. Openness to experience.

\begin{tabular}{lcccc}
\hline Variables & Aesthetics & Ideas & Actions & Values \\
\hline Ideas & $0.68^{*}$ & - & - & - \\
Actions & $0.57^{*}$ & $0.72^{*}$ & - & - \\
Values & $0.46^{*}$ & $0.63^{*}$ & $0.53^{*}$ & - \\
Imagination & $0.61^{*}$ & $0.71^{*}$ & $0.70^{*}$ & - \\
Mean & 3.91 & 3.76 & 3.99 & $0.61^{*}$ \\
Standard deviation & 0.68 & 0.57 & 0.55 & 3.91 \\
Alpha & 0.80 & 0.71 & 0.73 & 0.55 \\
Omega & 0.79 & 0.70 & 0.73 & 0.46 \\
\hline
\end{tabular}

$*, p<0.001$.

TABLE 1e: Inter-factor correlations of scales on Basic Traits Inventory. Agreeableness.

\begin{tabular}{|c|c|c|c|c|c|}
\hline Variables & Straightforwardness & Compliance & Prosocial tendencies & Modesty & Tendermindedness \\
\hline Compliance & $0.67^{*}$ & - & - & - & - \\
\hline Prosocial tendencies & $0.63 *$ & $0.61 *$ & - & - & - \\
\hline Modesty & $0.63^{*}$ & $0.61 *$ & $0.68^{*}$ & - & - \\
\hline Tendermindedness & $0.63 *$ & $0.67 *$ & $0.75 *$ & $0.75 *$ & - \\
\hline Mean & 3.97 & 3.77 & 3.88 & 3.83 & 4.03 \\
\hline Standard deviation & 0.58 & 0.55 & 0.57 & 0.51 & 0.52 \\
\hline Alpha & 0.72 & 0.68 & 0.75 & 0.60 & 0.77 \\
\hline Omega & 0.72 & 0.68 & 0.74 & 0.44 & 0.77 \\
\hline
\end{tabular}

$*, p<0.001$.

when facets with low internal consistency reliabilities and inter-factor correlations were removed in later analyses, as evident with the fit reported for the oblique lower-order model for Extroversion and Agreeableness in Table 2. The fit statistics for an oblique lower-order confirmatory factor model for Neuroticism $\left(\chi^{2}[d f]=3550.79\right.$ [521]; CFI $=0.91$;
$\mathrm{TLI}=0.90 ;$ SRMR $=0.06 ;$ RMSEA $=0.07$ [0.07; 0.07]), Conscientiousness $\left(\chi^{2}[d f]=3268.39\right.$ [769]; CFI = 0.93; $\mathrm{TLI}=0.93 ;$ SRMR $=0.05 ;$ RMSEA $=0.05[0.05 ; 0.05])$ and Openness to Experience $\left(\chi^{2}[d f]=2424.85\right.$ [454]; CFI = 0.91; $\mathrm{TLI}=0.91 ;$ SRMR $=0.06$; $\mathrm{RMSEA}=0.06[0.06 ; 0.06])$ were satisfactory. 
TABLE 2: Fit statistics of different factor models.

\begin{tabular}{|c|c|c|c|c|c|c|c|c|c|}
\hline No & Description & $\chi^{2}$ & $\Delta \chi^{2}$ & $d f$ & CFI & TLI & SRMR & RMSEA & $90 \% \mathrm{Cl}$ of RMSEA \\
\hline \multicolumn{10}{|c|}{ Extraversion } \\
\hline Test & Bifactor model (3-2) & 851.26 & - & 139 & 0.94 & 0.92 & 0.05 & 0.06 & $0.06 ; 0.07$ \\
\hline Model 4 & Oblique lower-order model & 999.62 & $148.36^{*}$ & 149 & 0.93 & 0.92 & 0.06 & 0.07 & $0.06 ; 0.07$ \\
\hline Model 3 & Higher-order model (3-2) & 999.62 & $148.36 *$ & 149 & 0.93 & 0.92 & 0.06 & 0.07 & $0.06 ; 0.07$ \\
\hline Model 2 & Single-factor model & 3381.50 & $2530.24 *$ & 152 & 0.72 & 0.68 & 0.10 & 0.13 & $0.13 ; 0.13$ \\
\hline Model 1 & Orthogonal first-order model & 4286.74 & $3435.48^{*}$ & 152 & 0.64 & 0.60 & 0.18 & 0.15 & $0.14 ; 0.15$ \\
\hline \multicolumn{10}{|c|}{ Neuroticism } \\
\hline Test & Bifactor model (4-2) & 3437.88 & - & 500 & 0.91 & 0.90 & 0.06 & 0.07 & $0.07 ; 0.07$ \\
\hline Model 4 & Oblique lower-order model & 3550.79 & $112.91 *$ & 521 & 0.91 & 0.90 & 0.06 & 0.07 & $0.07 ; 0.07$ \\
\hline Model 3 & Higher-order model (4-2) & 3780.24 & $342.36 *$ & 523 & 0.90 & 0.89 & 0.06 & 0.07 & $0.07 ; 0.07$ \\
\hline Model 2 & Single-factor model & 6381.80 & $2943.92 *$ & 527 & 0.82 & 0.81 & 0.08 & 0.10 & $0.09 ; 0.10$ \\
\hline Model 1 & Orthogonal first-order model & 23994 & $20556.12 *$ & 527 & 0.29 & 0.25 & 0.32 & 0.19 & $0.19 ; 0.19$ \\
\hline \multicolumn{10}{|c|}{ Conscientiousness } \\
\hline Test & Bifactor model (5-2) for aspects & 2798.57 & - & 737 & 0.95 & 0.94 & 0.04 & 0.05 & $0.05 ; 0.05$ \\
\hline Model 4 & Oblique lower-order model & 3268.39 & $469.82 *$ & 769 & 0.93 & 0.93 & 0.05 & 0.05 & $0.05 ; 0.05$ \\
\hline Model 3 & Higher-order model (5-2) for aspects & 3244.84 & $446.27 *$ & 773 & 0.94 & 0.93 & 0.05 & 0.05 & $0.05 ; 0.05$ \\
\hline Model 2 & Single-factor model & 6041.58 & $3243.01 *$ & 779 & 0.86 & 0.86 & 0.06 & 0.07 & $0.07 ; 0.08$ \\
\hline Model 1 & Orthogonal first-order model & 30204.84 & $27406.27 *$ & 779 & 0.23 & 0.19 & 0.35 & 0.17 & $0.17 ; 0.18$ \\
\hline \multicolumn{10}{|c|}{ Openness to experience } \\
\hline Test & Bifactor model (4-2) for aspects & 1848.35 & - & 278 & 0.93 & 0.91 & 0.05 & 0.07 & $0.06 ; 0.07$ \\
\hline Model 4 & Oblique lower-order model & 1950.58 & $102.23 *$ & 293 & 0.92 & 0.91 & 0.05 & 0.07 & $0.06 ; 0.07$ \\
\hline Model 3 & Higher-order model (4-2) for aspects & 1945.73 & $97.38 *$ & 295 & 0.92 & 0.91 & 0.05 & 0.07 & $0.06 ; 0.07$ \\
\hline Model 2 & Single-factor model & 4598.04 & $2749.69 *$ & 299 & 0.80 & 0.78 & 0.08 & 0.11 & $0.10 ; 0.11$ \\
\hline Model 1 & Orthogonal first-order model & 12698.99 & $10850.64 *$ & 299 & 0.42 & 0.37 & 0.25 & 0.18 & $0.18 ; 0.18$ \\
\hline \multicolumn{10}{|c|}{ Agreeableness } \\
\hline Test & Bifactor model (4-2) for aspects & 1876.58 & - & 321 & 0.93 & 0.91 & 0.05 & 0.06 & $0.06 ; 0.06$ \\
\hline Model 4 & Oblique lower-order model & 2453.76 & $577.18^{*}$ & 344 & 0.90 & 0.89 & 0.06 & 0.07 & $0.07 ; 0.07$ \\
\hline Model 3 & Higher-order model (4-2) for aspects & 2441.31 & $564.73^{*}$ & 345 & 0.90 & 0.89 & 0.06 & 0.07 & $0.07 ; 0.07$ \\
\hline Model 2 & Single-factor model & 4742.14 & $2865.56^{*}$ & 350 & 0.79 & 0.77 & 0.08 & 0.10 & $0.10 ; 0.10$ \\
\hline Model 1 & First-order model & 13203.48 & $11326.90 *$ & 350 & 0.39 & 0.34 & 0.24 & 0.17 & $0.17 ; 0.17$ \\
\hline
\end{tabular}

Note: CFI, comparative fit index; TLI, Tucker-Lewis index; SRMR, standardised root mean square residual; RMSEA, root mean square error of approximation. $*, p<0.001$.

In general, evidence from Table 1 suggests that the facets associated with each trait are highly correlated, except for the correlation of Excitement Seeking with other facets of Extraversion. This finding corroborates the claim that personality facets can be empirically categorised under broad traits with the population under investigation. Most of the facets yielded satisfactory inter-item reliability coefficients (omega $\geq 0.66$ ), apart from the scales for Values (omega $=0.42)$ and Modesty (omega $=0.44)$. These lower reliability scores are in line with previous findings (Taylor \& De Bruin, 2017).

The difference in reliability between alpha and omega with Modesty could have been caused by the violation of the condition for tau-equivalence, which made alpha a less conservative estimate of the true population reliability (Dunn, Baguley, \& Brunsden, 2014).

\section{Confirmatory factor analysis}

To determine whether eight hierarchical composites could be derived from the facets of the BTI, the fit of different factor models proposed by Credé and Harms (2015) was investigated for each trait and are reported in Table 2. Each of the five models' chi-square statistics is compared with the test model with two personality aspects. With Openness to
Experience and Agreeableness, the respective facets Values and Modesty were dropped because of low reliabilities reported. In Extraversion, the Excitement Seeking facet was dropped from both Assertiveness and Enthusiasm because of the low inter-factor loadings reported. Liveliness was dropped because of several negative factor variances reported, which could have been caused by model misspecification (Brown, 2006; Schumacker \& Lomax, 2010). The removal of the Liveliness facet also improved the overall fit of the factor models specified. Because of the removal of Liveliness and Excitement Seeking, a hierarchical composite for Assertiveness could not be specified, which made the assessment of $\mathrm{H} 1$ unfeasible. The first two items from the Compliance facet of Agreeableness and the sixth item of the Gregariousness facet of Extraversion were dropped because of negative factor variance reported, which could also have been caused by model specification error (Brown, 2006; Schumacker \& Lomax, 2010).

As reflected in Table 2, the bifactor structure of DeYoung et al.'s (2007) two-personality aspects yielded a better fit to the data than the orthogonal first-order, single-factor, higherorder and oblique lower-order structures in most of the traits. The bifactor model with two personality aspects for Neuroticism yielded a similar fit to the oblique lower-order model. 
TABLE 3: Bifactor statistical indices for personality aspects

\begin{tabular}{|c|c|c|c|c|c|}
\hline Variables & ECV & PUC & OmegaH & $\boldsymbol{H}$ & FD \\
\hline Enthusiasm (g) & 0.56 & 0.55 & 0.64 & 0.82 & 0.85 \\
\hline Positive affectivity & 0.25 & & 0.43 & 0.67 & 0.81 \\
\hline Gregariousness & 0.18 & & 0.26 & 0.56 & 0.72 \\
\hline Withdrawal (g) & 0.80 & 0.69 & 0.89 & 0.95 & 0.96 \\
\hline Depression & 0.05 & & 0.10 & 0.41 & 0.67 \\
\hline Self-consciousness & 0.07 & & 0.19 & 0.52 & 0.73 \\
\hline Anxiety & 0.08 & & 0.18 & 0.59 & 0.83 \\
\hline Industriousness (g) & 0.81 & 0.53 & 0.84 & 0.93 & 0.94 \\
\hline Effort & 0.14 & & 0.26 & 0.59 & 0.79 \\
\hline Self-discipline & 0.05 & & 0.08 & 0.33 & 0.56 \\
\hline Orderliness (g) & 0.76 & 0.68 & 0.87 & 0.95 & 0.96 \\
\hline Order & 0.13 & & 0.28 & 0.70 & 0.85 \\
\hline Dutifulness & 0.06 & & 0.14 & 0.46 & 0.70 \\
\hline Prudence & 0.05 & & 0.15 & 0.47 & 0.77 \\
\hline Aesthetic openness (g) & 0.62 & 0.70 & 0.77 & 0.90 & 0.90 \\
\hline Aesthetics & 0.17 & & 0.42 & 0.69 & 0.81 \\
\hline Actions & 0.11 & & 0.28 & 0.57 & 0.73 \\
\hline Imagination & 0.10 & & 0.26 & 0.54 & 0.71 \\
\hline Politeness (g) & 0.64 & 0.54 & 0.71 & 0.83 & 0.87 \\
\hline Straightforwardness & 0.19 & & 0.22 & 0.59 & 0.76 \\
\hline Compliance & 0.17 & & 0.27 & 0.57 & 0.76 \\
\hline Compassion (g) & 0.71 & 0.53 & 0.77 & 0.89 & 0.90 \\
\hline Prosocial tendencies & 0.17 & & 0.26 & 0.60 & 0.75 \\
\hline Tender-mindedness & 0.12 & & 0.20 & 0.50 & 0.68 \\
\hline
\end{tabular}

Note: ECV, explained common variance; PUC, percentage of uncontaminated correlations; $H$, construct replicability; FD, factor determinacy. Absolute relative parameter bias (ARPB) for Enthusiasm $=0.22 ;$ Withdrawal $=0.06$; Industriousness $=0.08$; Orderliness $=0.08 ;$ Aesthetic openness $=0.13$; Compassion $=0.10$ and Politeness $=0.14$.

\section{Bifactor statistical indices}

The superiority of bifactor models' fit indices, relative to other confirmatory factor models, could be a symptom of overfitting (Bonifay, Lane, \& Reise, 2017). Rodriguez, Reise and Haviland (2016) recommend that bifactor statistical indices are calculated to determine the practical meaningfulness of group factors, such as the explained common variance $(\mathrm{ECV})$, coefficient omega hierarchical $\left(\omega_{\mathrm{h}}\right)$, construct replicability $(\mathrm{H})$, factor determinacy (FD), percentage of uncontaminated correlations (PUC) and absolute relative parameter bias (ARPB). Group factors of each personality aspect were considered more plausible when $\omega_{\mathrm{h}}, \mathrm{H}$ and $\mathrm{FD}^{2}$ were $>0.50,0.70$, and 0.70, respectively (Dueber, 2017; Reise, Bonifay, \& Haviland, 2013). Explained common variance for the general factor $(g)>0.70$ and PUC $>0.80$ were indicative of unidimensionality (Reise et al., 2013). When PUC is $<0.80, \mathrm{ECV}$ of $g$ is $>0.60$ and OmegaH of $g$ is $>0.70$, the factor structure may still be interpreted as unidimensional (Reise et al., 2013). Absolute relative parameter bias of $10 \%$ to $15 \%$ was indicative of little difference in the factor loadings between a single-factor model and the general factor in a bifactor model (Rodriguez et al., 2016). Bifactor statistical indices were calculated from the standardised factor loadings in the bifactor models of the two personality aspects (Dueber, 2020) in $R$ (R Core Team, 2016). Bifactor statistical indices were only calculated for the seven personality aspects for which the calculation of total scores might be meaningful. The bifactor statistical indices are reported in Table 3.
The bifactor statistical indices in Table 3 provide evidence for:

$\mathbf{H}_{2}$ : A unidimensional model for Enthusiasm and diminished biasing effect for the group factors of Positive Affectivity and Gregariousness. An interpretation of Enthusiasm as a total score, instead of a hierarchical factor with sub-scores for Positive Affectivity and Gregariousness, might be a more appropriate representation of the data.

$\mathbf{H}_{3}$ : A unidimensional model for Withdrawal and diminished biasing effect for the group factors of Depression, Self-Consciousness and Anxiety. An interpretation of Withdrawal as a total score, instead of a hierarchical factor with sub-scores for Depression, Self-Consciousness and Anxiety might be a more appropriate representation of the data.

$\mathbf{H}_{4}$ : A unidimensional model for Industriousness and diminished biasing effect for the group factors of Effort and Self-Discipline. An interpretation of Industriousness as a total score, instead of a hierarchical factor with sub-scores for Effort and Self-Discipline, might be a more appropriate representation of the data.

$\mathbf{H}_{5}$ : A unidimensional model for Orderliness and diminished biasing effect for the group factors of Order, Dutifulness and Prudence. An interpretation of Orderliness as a total score, instead of a hierarchical factor with sub-scores for Order, Dutifulness and Prudence, might be a more appropriate representation of the data.

$\mathbf{H}_{6}$ : A unidimensional model for Aesthetic Openness and diminished biasing effect for the group factors of Aesthetics, Actions and Imagination. An interpretation of Aesthetic Openness as a total score, instead of a hierarchical factor with sub-scores for Aesthetics, Actions and Imagination, might be a more appropriate representation of the data.

$\mathbf{H}_{7}$ : A unidimensional model for Compassion and diminished biasing effect for the group factors of Prosocial Tendencies and Tender-mindedness. An interpretation of Compassion as a total score, instead of a hierarchical factor with sub-scores for Prosocial Tendencies and Tender-mindedness, might be a more appropriate representation of the data.

$\mathbf{H}_{8}$ : A unidimensional model for Politeness and diminished biasing effect for the group factors of Straightforwardness and Compliance. An interpretation of Politeness as a total score instead of a hierarchical factor with sub-scores for Straightforwardness and Compliance, might be a more appropriate representation of the data.

\section{Discussion}

Evidence based on the procedure proposed by Credé and Harms (2015), supports the hierarchical structure of seven of the 10 personality aspects in the BTI. However, interpretations of sub-scores on facets, independent of the total scores for personality aspects, should be tempered by the evidence provided by bifactor statistical indices in Table 3. Interpretations of facet-level sub-scores might be relevant for development purposes when anomalous results exist for a candidate but should still be interpreted in light of total aspect or trait score.

For this study, we decided to drop the facet of Excitement Seeking from Extraversion because of its low correlation with other facets of Extraversion. Previous research shows that Excitement Seeking is related to both Openness to Experience 
and Extraversion (Aluja, García, \& García, 2003; Hough, Oswald, \& Ock, 2015; Taylor \& De Bruin, 2017). Other scholars argue that Excitement Seeking might be related to an alternative broader trait such as Spontaneity, Plasticity or Impulsivity (DeYoung, 2015; DeYoung et al., 2007; Hofstee et al., 1992). Liveliness was dropped because of several negative factor variances reported, which could have been caused by model misspecification (Brown, 2006; Schumacker \& Lomax, 2010). Liveliness and Excitement Seeking might share communality and could be investigated in the future as an indication of Spontaneity, Plasticity or Impulsivity (DeYoung, 2015; DeYoung et al., 2007; Hofstee et al., 1992). Facet Playfulness in the South African Personality Inventory (SAPI) displays a strong loading on Extraversion (Morton, Hill, Meiring, \& De Beer, 2019) and appears invariant across ethnic groups in South Africa (Morton, Hill, Meiring, \& Van de Vijver, 2019). An adaptation of the facet Playfulness might be a useful alternative to Liveliness and Excitement Seeking or a meaningful addition to trait Extraversion on the BTI. The number of facets available for Assertiveness did not enable the inspection of H1. Modesty was dropped from Agreeableness and Values dropped from Openness to Experience because of the facets' low reliability. The low reliabilities are similar to findings reported in prior studies conducted on the BTI (Taylor \& De Bruin, 2017). Constructs, such as the Interpersonal Relatedness and BroadMindedness from the SAPI (Morton, Hill, Meiring, \& De Beer, 2019), might be more reliable additions than facets Modesty and Values. A revised version of the BTI might include additional facets to inspect the hierarchical structure of Assertiveness, Volatility and Intellect.

Based on the above findings, we propose working definitions for the 10 personality aspects in Table 4 . These definitions are phrased in terms of their implications for the workplace.

This study has important implications for assessment in the workplace. Firstly, the potential of personality aspects from the BTI to predict aspects of performance at the corresponding

TABLE 4: Potential work-related definitions for the 10 personality aspects.

\begin{tabular}{|c|c|}
\hline Dimension & Definition \\
\hline $\begin{array}{l}\text { Assertiveness/ } \\
\text { ascendance }\end{array}$ & $\begin{array}{l}\text { The degree to which employees strive for social status or } \\
\text { have a significant interpersonal impact }\end{array}$ \\
\hline Enthusiasm & $\begin{array}{l}\text { The degree to which employees are cheerful, friendly and } \\
\text { easy to get to know }\end{array}$ \\
\hline $\begin{array}{l}\text { Volatility/affective } \\
\text { instability }\end{array}$ & $\begin{array}{l}\text { The degree to which employees externalise stress and easily } \\
\text { express their anger, frustration and irritation to others }\end{array}$ \\
\hline Withdrawal & $\begin{array}{l}\text { The degree to which employees internalise stress and } \\
\text { experience negative emotions at work }\end{array}$ \\
\hline Industriousness & $\begin{array}{l}\text { The degree to which employees are dedicated to their } \\
\text { work and set high standards for themselves }\end{array}$ \\
\hline Orderliness & $\begin{array}{l}\text { The degree to which employees are cautious and } \\
\text { meticulous when performing work tasks }\end{array}$ \\
\hline Intellect/ideas & $\begin{array}{l}\text { The degree to which employees think about work creatively } \\
\text { and enjoy coming up with inventive ideas }\end{array}$ \\
\hline Aesthetic openness & $\begin{array}{l}\text { The degree to which employees appreciate artistic pursuits } \\
\text { and are willing to engage with change in the workplace }\end{array}$ \\
\hline Politeness & $\begin{array}{l}\text { The degree to which employees are well-mannered and } \\
\text { perceived as pleasant by co-workers }\end{array}$ \\
\hline Compassion & $\begin{array}{l}\text { The degree to which employees are empathetic and } \\
\text { helpful towards co-workers }\end{array}$ \\
\hline
\end{tabular}

Source: Adapted from DeYoung et al. (2007). Between facets and domains: 10 aspects of the Big Five. Journal of Personality and Social Psychology, 93(5), 883-885. level of specificity, such as task, contextual (Motowidlo \& Van Scotter, 1994), adaptive, (Pulakos, Arad, Donovan, \& Plamondon, 2000), counterproductive (Spector et al., 2006) or leadership performance (Yukl, 2012) can now be investigated. Secondly, personality aspects provide practitioners with another, perhaps more parsimonious, layer of interpretability to help their clients make more informed decisions about the selection of applicants (Judge et al., 2013).

Some limitations should be considered when interpreting the results. Hierarchical structures could not be inspected for three of the 10 personality aspects. The addition of facets, with DeYoung et al.'s (2007) conceptualisation of the 10 personality aspects as the point of departure might be a prospect for a revised version of the BTI. An inspection of the bifactor statistical indices further reveals a more unidimensional rather than hierarchical structure amongst the seven of the 10 personality aspects. This suggests that the personality aspects might be a more parsimonious, albeit not hierarchical, representation of the common variance amongst the facets in the traits.

Psychology is currently facing challenges related to the replicability of the discipline's findings (Efendic \& Van Zyl, 2019). Even though this study provides evidence for the existence of personality aspects, albeit not hierarchical aspects, amongst South African employees, the proposed factor structure must be replicated with larger samples than the one used in the current study before definitive statements are made about the manifestation of the 10 personality aspects amongst the facets of the BTI. An investigation of the 10 personality aspects amongst alternative measures of the Big Five in South Africa, such as the NEO-PI-R (Laher, 2013) or the South African Personality Inventory (Fetvadjiev, Meiring, Van de Vijver, Nel, \& Hill, 2015), might serve as additional evidence for the manifestation of the 10 personality aspects amongst facets of personality measures. Other measures might also yield evidence for the hierarchical structure of the 10 personality aspects. In doing so, a more robust case can be built to argue the existence of DeYoung et al.'s (2007) 10 personality aspects in South Africa. The self-report data are the only point of reference. Further studies on the prediction of specific facets of job performance from the personality aspects could bolster the scientific and practical usefulness of the 10 personality aspects in South Africa (Judge et al., 2013).

Finally, Africa is in a unique position in that it has geographical areas stretching across the northern and southern hemispheres. It might be meaningful to determine if the findings on the 10 personality aspects are replicable in the northern hemispheres of Africa as well, thereby giving heed to Van de Vliert and Van Lange's (2019) call for cross-longitudinal research in psychology.

\section{Conclusion}

The current study supports the notion that 10 personality aspects might provide a more parsimonious representation, 
but not necessarily a hierarchical representation, of the common variance amongst the facets of the BTI. The findings hold promise for further research into the predictive validity of these personality aspects for specific levels of performance in the workplace. Further replications are required before it can be conclusively shown that DeYoung et al.'s (2007) 10 personality aspects represent a more parsimonious representation of personality facets in the South African context. Whilst this model does not override the five-factor model of personality, it does allow for the prediction of more specific work-related outcomes based on parsimonious factors at a greater level of specificity than the Big Five.

\section{Acknowledgements Competing interests}

The authors declare that they have no financial or personal relationships that may have inappropriately influenced them in writing this article.

\section{Authors' contributions}

X.v.L. and N.T. developed the conceptual framework and analysed the data.

\section{Funding information}

This research received no specific grant from any funding agency in the public, commercial, or not-for-profit sectors.

\section{Data availability}

Coefficients based on the bifactor confirmatory factor analysis are available on request from the corresponding author, X.v.L.

\section{Disclaimer}

The views and opinions expressed in this article are those of the authors and do not necessarily reflect the official policy or position of any affiliated agency of the authors.

\section{References}

Akaike, H. (1987). Factor analysis and AIC. Psychometrika, 52(3), 317-332. https://doi. org/10.1007/BF02294359

Aluja, A., García, Ó., \& García, L.F. (2003). Relationships among extraversion, openness to experience, and sensation seeking. Personality and Individual Differences, 35(3), 671-680. https://doi.org/10.1016/S0191-8869(02)00244-1

Anglim, J., \& Grant, S.L. (2014). Incremental criterion prediction of personality facets over factors: Obtaining unbiased estimates and confidence intervals. Journal of Research in Personality, 53, 148-157. https://doi.org/10.1016/j.jrp.2014.10.005

Barrick, M.R., \& Mount, M.K. (2005). Yes, personality matters: Moving on to more important matters. Human Performance, 18(4), 359-372. https://doi. org/10.1207/s15327043hup1804_3

Beauducel, A., \& Yorck Herzberg, P. (2009). On the performance of maximum likelihood versus means and variance adjusted weighted least squares estimation in CFA. Structural Equation Modeling: A Multidisciplinary Journal, 13(2), 186-203. https://doi.org/10.1207/s15328007sem1302_2

Beaujean, A.A. (2014). Latent variable modeling using R: A step-by-step guide. New York, NY: Routledge.

Bonifay, W., Lane, S.P., \& Reise, S.P. (2017). Three concerns with applying a bifactor model as a structure of psychopathology. Clinical Psychological Science, 5(1), 184-186. https://doi.org/10.1177/2167702616657069

Brown, T.A. (2006). Confirmatory factor analysis for applied research. New York, NY: The Guilford Press.
Browne, M.W., \& Cudeck, R. (1992). Alternative ways of assessing model fit. Sociological Methods \& Research, 21(2), 230-258. https://doi. org/10.1177/0049124192021002005

Costa, P.T., \& McCrae, R.R. (1992). The NEO-PI-R professional manual. Odessa, FL: Psychological Assessment Resources.

Credé, M., \& Harms, P.D. (2015). 25 years of higher-order confirmatory factor analysis in the organizational sciences: A critical review and development of reporting recommendations. Journal of Organizational Behavior, 36(6), 845-872. https:// recommend10.1002/job.2008

Cronbach, L.J. (1951). Coefficient alpha and the internal structure of tests. Psychometrika, 16(3), 297-334. https://doi.org/10.1007/BF02310555

Cronbach, L.J., \& Gleser, G.C. (1965). Psychological tests and personnel decisions (2nd ed.). Urbana, IL: University of Illinois Press.

Department of Basic Education. (2019). Annual performance plan / 2018/2019. Retrieved from https://www.education.gov.za/Portals/0/Documents/Reports/ Annual\%20Performance\%20Plan\%20201819.pdf?ver=2018-03-14-121624-263

DeYoung, C.G. (2015). Cybernetic big five theory. Journal of Research in Personality, 56, 33-58. https://doi.org/10.1016/j.jrp.2014.07.004

DeYoung, C.G., Quilty, L.C., \& Peterson, J.B. (2007). Between facets and domains: 10 aspects of the Big Five. Journal of Personality and Social Psychology, 93(5), 880-896. https://doi.org/10.1037/0022-3514.93.5.880

DiStefano, C. (2002). The impact of categorization with confirmatory factor analysis. Structural Equation Modeling: A Multidisciplinary Journal, 9(3), 327-346. https:// doi.org/10.1207/S15328007SEM0903_2

DiStefano, C., \& Morgan, G.B. (2014). A comparison of diagonal weighted least squares robust estimation techniques for ordinal data. Structural Equation Modeling: A Multidisciplinary Journal, 21(3), 425-438. https://doi.org/10.1080/ 10705511.2014.915373

Dueber, D.M. (2017). Bifactor indices calculator: A microsoft excel-based tool to calculate various indices relevant to bifactor CFA models. Lexington, KY UKnowledge, University of Kentucky. https://doi.org/10.13023/edp.tool.01

Dueber, D.M. (2020). Bifactor indices calculator. Retrieved from https://cran.r-project. $\mathrm{org} / \mathrm{src} /$ contrib/Archive/BifactorlndicesCalculator/

Dunn, T.J., Baguley, T., \& Brunsden, V. (2014). From alpha to omega: A practical solution to the pervasive problem of internal consistency estimation. British Journal of Psychology, 105(3), 399-412. https://doi.org/10.1111/bjop.12046

Efendic, E., \& Van Zyl, L.E. (2019). On reproducibility and replicability: Arguing for open science practices and methodological improvements at the South African Journal of Industrial Psychology. SA Journal of Industrial Psychology, 45. https://doi org/10.4102/sajip.v45i0.1607

Fetvadjiev, V.H., Meiring, D., Van de Vijver, F.J.R., Nel, J.A., \& Hill, C. (2015). The South African Personality Inventory (SAPI): A culture-informed instrument for the country's main ethnocultural groups. Psychological Assessment, 27(3), 827-837. https://doi.org/10.1037/pas0000078

Finch, W. H., \& French, B. F. (2015). Latent variable modeling with R. New York, NY: Routledge.

Hofstee, W.K., De Raad, B., \& Goldberg, L.R. (1992). Integration of the Big Five and circumplex approaches to trait structure. Journal of Personality and Social Psychology, 63(1), 146-163. https://doi.org/10.1037/0022-3514.63.1.146

Hough, L.M., Oswald, F.L., \& Ock, J. (2015). Beyond the Big Five: New directions for personality research and practice in organizations. Annual Review of Organizational Psychology and Organizational Behavior, 2(1), 183-209. https:// doi.org/10.1146/annurev-orgpsych-032414-111441

Hu, L., \& Bentler, P.M. (1999). Cutoff criteria for fit indexes in covariance structure analysis: Conventional criteria versus new alternatives. Structural Equation Modeling: A Multidisciplinary Journal, 6(1), 1-55. https://doi.org/10.1080/10705519909540118

Jang, K.L., Livesley, W.J., Angleitner, A., Reimann, R., \& Vernon, P.A. (2002). Genetic and environmental influences on the covariance of facets defining the domains of the five-factor model of personality. Personality and Individual Differences, 33(1) 83-101. https://doi.org/10.1016/S0191-8869(01)00137-4

Jorgensen, T.D., Pornprasertmanit, S., Schoemann, A., \& Rosseel, Y. (2019). Useful tools for structural equation modeling. Retrieved from https://cran.r-project.org/ web/packages/semTools/semTools.pdf

Judge, T.A., Rodell, J.B., Klinger, R.L., Simon, L.S., \& Crawford, E.R. (2013). Hierarchical representations of the five-factor model of personality in predicting job performance: Integrating three organizing frameworks with two theoretical perspectives. Journal of Applied Psychology, 98(6), 875-925. https://doi. org/10.1037/a0033901

Laajaj, R., Macours, K., Hernandez, D.A.P., Arias, O., Gosling, S.D., Potter, J., ... Vakis, R. (2019). Challenges to capture the big five personality traits in non-WEIRD populations. Science Advances, 5(7), eaaw5226. https://doi.org/10.1126/sciadv.aaw5226

Laher, S. (2013). The NEO-PI-R in South Africa. In S. Laher \& K. Cockcroft (Eds.), Psychological assessment in South Africa: Research and applications (pp. 257-269). Johannesburg, South Africa: Wits University Press.

Li, C.-H. (2016). Confirmatory factor analysis with ordinal data: Comparing robust maximum likelihood and diagonally weighted least squares. Behavior Research Methods, 48(3), 936-949. https://doi.org/10.3758/s13428-015-0619-7

Mcabee, T.S., Oswald, L.F., \& Connelly, S.B. (2014). Bifactor models of personality and college student performance: A broad vs narrow view. European Journal of Personality, 28(6), 604-619. https://doi.org/10.1002/per.1975

McDonald, R.P. (1999). Test theory: A unified treatment. Mahwah, NJ: Erlbaum. 
Morton, N., Hill, C., Meiring, D., \& De Beer, L.T. (2019). Investigating the factor structure of the South African Personality Inventory - English version. SA Journal of Industrial Psychology, 45(0), 1-13. https://doi.org/10.4102/sajip.v45i0.1556

Morton, N., Hill, C., Meiring, D., \& Van de Vijver, F.J.R. (2019). Investigating measurement invariance in the South African Personality Inventory: English version. South African Journal of Psychology, 50(2), 274-289. https://doi. org/10.1177/0081246319877537

Motowidlo, S.J., \& Van Scotter, J.R. (1994). Evidence that task performance should be distinguished from contextual performance. Journal of Applied Psychology, 79(4), 475-480. https://doi.org/10.1037/0021-9010.79.4.475

Ones, D.S., Dilchert, S., Viswesvaran, C., \& Judge, T.A. (2007). In support of personality assessment in organizational settings. Personnel Psychology, 60(4), 995-1027. https://doi.org/10.1111/j.1744-6570.2007.00099.x

Ones, D.S., Viswesvaran, C., \& Dilchert, S. (2005). Personality at work: Raising awareness and correcting misconceptions. Human Performance, 18(4), 389-404. https://doi.org/10.1207/s15327043hup1804_5

Pletzer, J.L., Oostrom, J.K., Bentvelzen, M., \& De Vries, R.E. (2020). Comparing domainand facet-level relations of the HEXACO personality model with workplace
deviance: A meta-analysis. Personality and Individual Differences, 152, 1-11. deviance: A meta-analysis. Personality and
https://doi.org/10.1016/j.paid.2019.109539

Pulakos, E.D., Arad, S., Donovan, M.A., \& Plamondon, K.E. (2000). Adaptability in the workplace: Development of a taxonomy of adaptive performance. Journal of Applied Psychology, 85(4), 612-624. https://doi.org/10.1037/0021-9010.85.4.612

$\mathrm{R}$ Core Team. (2016). R: A language and environment for statistical computing
Retrieved from https://cran.r-project.org/doc/manuals/r-release/fullrefman.pdf Raftery, A.E. (1995). Bayesian model selection in social research. Sociological Methodology, 25, 111-163. https://doi.org/10.2307/271063

Reise, S.P., Bonifay, W.E., \& Haviland, M.G. (2013). Scoring and modeling psychological measures in the presence of multidimensionality. Journal of Personality
Assessment, 95(2), 129-140. https://doi.org/10.1080/00223891.2012.725437

Revelle, W., \& Zinbarg, R.E. (2009). Coefficients alpha, beta, omega, and the glb: Comments on sijtsma. Psychometrika, 74(1), 145-154. https://doi.org/10.1007/ s11336-008-9102-z

Rodriguez, A., Reise, S.P., \& Haviland, M.G. (2016). Evaluating bifactor models: Calculating and interpreting statistical indices. Psychological Methods, 21(2), 137-150. https://doi.org/10.1037/met0000045

Schumacker, R.E., \& Lomax, R.G. (2010). A beginner's guide to structural equation modeling. New York, NY: Taylor and Francis Group.
South African Reserve Bank. (2019). Quarterly Bulletin for March 2020. Retrieved from https://www.resbank.co.za/content/dam/sarb/publications/quarterly-bulletins/ quarterly-bulletin-publications/2020/9797/01Full-Quarterly-Bulletin---March-2020. pdf

Spector, P.E., Fox, S., Penney, L.M., Bruursema, K., Goh, A., \& Kessler, S. (2006). The dimensionality of counterproductivity: Are all counterproductive behaviors created equal? Journal of Vocational Behavior, 68(3), 446-460. https://doi. org/10.1016/j.jvb.2005.10.005

Statistics South Africa. (2019). Inequality trends in South Africa: A multidimensiona diagnostic of inequality. Retrieved from http://www.statssa.gov.za/publications/ Report-03-10-19/Report-03-10-192017.pdf

Taylor, N., \& De Bruin, G.P. (2017). Basic Traits Inventory: Technical manual. Johannesburg, South Africa: JVR Psychometrics.

Tett, R.P., Steele, J.R., \& Beauregard, R.S. (2003). Broad and narrow measures on both sides of the personality-job performance relationship. Journal of Organizationa Behavior, 24(3), 335-356. https://doi.org/10.1002/job.191

Transparancy International. (2019). Corruption perceptions index. Retrieved from https://images.transparencycdn.org/images/2019_CPI_Report_EN_200331_ 141425.pdf

Van Aarde, N., Meiring, D., \& Wiernik, B.M. (2017). The validity of the Big Five personality traits for job performance: Meta-analyses of South African studies. International Journal of Selection and Assessment, 25(3), 223-239. https://doi. org/10.1111/ijsa.12175

Van de Vliert, E., \& Van Lange, P.A.M. (2019). Latitudinal psychology: An ecological perspective on creativity, aggression, happiness, and beyond. Perspectives on Psychological Science, 14(5), 860-884. https://doi. org/10.1177/1745691619858067

Vandenberg, R.J., \& Lance, C.E. (2000). A review and synthesis of the measurement invariance literature: Suggestions, practices, and recommendations for organizational research. Organizational Research Methods, 3(1), 4-69. https:// doi.org/10.1177/109442810031002

Wiernik, B.M., Yarkoni, T., Giordano, C., \& Raghavan, M. (2020, April 22). Two, five, six eight (thousand): Time to end the dimension reduction debate!. PsyArXiv. https:// doi.org/10.31234/osf.io/d7jye

Yukl, G. (2012). Effective leadership behavior: What we know and what questions need more attention. Academy of Management Perspectives, 26(4), 66-85. https://doi.org/10.5465/amp.2012.0088 